\title{
A comunicação nas teorias das mídias digitais no Brasil e nos Estados Unidos
}

\section{Communication in the theories of digital media in Brazil and the United States}

\section{Tarcyanie Cajueiro Santos}

Doutora e Pós-Doutora em Ciências da Comunicação pela USP. Professora do Mestrado em Comunicação e Cultura da Universidade de Sorocaba - (Uniso).

$<$ tarcyanie@terra.com.br>

\section{RESUMO}

O objetivo geral é traçar um panorama de como as mídias digitais são estudadas pelos pesquisadores brasileiros e norte-americanos. O objetivo específico é rastrear como o conceito de comunicação aparece e é trabalhado por eles. O percurso teóricometodológico deriva-se de levantamento e análise bibliográfica, que na perspectiva brasileira, apoiase em pesquisadores que são referência na área. Do ponto de vista estadunidense, nos fundamentamos em artigos publicados no Journal of ComputerMediated Communication, referência no contexto norte-americano. Trata-se de uma pesquisa em andamento, que aponta para o caráter distinto da internet em relação a outras mídias, a transformação da comunicação e a dificuldade de encontrar unidades de análise coerentes devido à diversidade terminológica.

Palavras-chave: Comunicação. Mídias digitais. Pesquisas norteamericana e brasileira.

\begin{abstract}
The main objective is to give an overview of how digital media is being studied by Brazilian and American researchers. The specific objective is to trace how the concept of communication appears and how it is working. The theoretical-methodological approach derives from survey and literature review, which the Brazilian perspective, rests by researchers who have become reference in the area. From the US perspective, we rely on published in the Journal of Computer-Mediated Communication, reference in the North American context. This is an ongoing study, whose partial results points to the distinct character of the internet compared to other media, the transformation of communication and the difficulty of finding consistent units of analysis because of the terminological diversity.
\end{abstract}

Keywords: Communication. Digital media. US and Brazilian research.

\section{Introdução}

Este trabalho tem como objetivo geral traçar um panorama geral de como as mídias digitais são estudadas pelos pesquisadores brasileiros e norteamericanos. O objetivo específico é rastrear se o conceito de comunicação é utilizado pelos teóricos ao se reportarem a essas mídias e se, ao ser utilizado, de que forma ele é trabalhado. Configuram-se como problemas: Quais são os principais aportes teóricos que aparecem diante desta outra mídia? E quais tipos de investigações estão se desenvolvendo sobre esta temática? Como os pesquisadores da comunicação norte-americano e brasileiro pensam a comunicação a partir das novas tecnologias, tendo a internet como seu grande 
vetor de tendências e articulações? Com isso, não queremos responder à questão o que é comunicação, mas procurar novas perspectivas teóricas a partir das transformações midiáticas.

Pressupomos que as mídias digitais trazem consigo mudanças, abarcando diversas dimensões de nossa existência que apontam questões que "antes não se manifestavam de forma tão evidente como agora" (Felinto, 2011, p.5), pois "o digital (e as formas de conhecimento que lhes são culturalmente coletâneas) favoreceu as problematização do próprio cerne da noção de comunicação" (p.6). 0 olhar que lançamos à comunicação dissocia-se de uma perspectiva ontológica, associando-se a uma narrativa que está sendo construída por áreas de pesquisa cujo objeto trás consigo problemas e questões.

Diante de uma imensidão de trabalhos, optamos, na perspectiva brasileira, por pesquisadores que já se tornaram referência na área, sendo citados em diversos artigos que tratam do tema. Sob a perspectiva estadunidense, nos apoiamos em trabalhos publicados no Journal of Computer-Mediated Communication, que foi inaugurado em 1996 e tem tido grande repercussão por parte da comunidade de pesquisadores norte-americana.

\section{Panorama}

Os pesquisadores da comunicação no Brasil tem se debatido ao longo do tempo com inúmeras questões acerca do seu objeto. Não háconsenso sobre oque constituiria esta área. De maneira geral, o objeto da comunicação ora é pensado a partir de interações sociais, ora como derivado das mídias. Mesmo partindose do pressuposto de que o objeto sejam as mídias, ainda assim as dificuldades de investigação estão presentes. França (2001) é uma autora que aponta para o problema de conceber a comunicação a partir da empiria. Para ela, ao contrário do que se pensa à primeira vista, o fato de pensarmos a comunicação tendo a mídia como objeto não resolve o problema de identidade epistemológica da área. Na medida em que se estuda mais detalhadamente este objeto, percebese que ele apresenta dois grandes problemas: o de ser demasiadamente amplo e também muito restrito. Nesses termos, a amplitude ou falta de especificidade diz respeito a um objeto (mídia) que, mais do que definidor de uma área, seria uma dimensão fundamental e caracterizadora da sociedade contemporânea; por outro lado, a relação da mídia com a sua dimensão técnica e a importância dada ao seu papel de suporte restringe em muito o nível de alcance da análise deste objeto. Por isso, segundo esta autora: 
Fechar o objeto da comunicação no campo das mídias é uma operação redutora, ao excluir as inúmeras práticas comunicativas que edificam e marcam a vida social - e não passam pelo terreno das mediações tecnológicas (por exemplo, o rumor, as relações de vizinhança e suas formas comunicativas, os teatros ou encenações urbanas - entre outras) (França, 2001, p.5).

Contudo, se este recorte apresenta problemas, também não podemos prescindir de pensar a comunicação a partir do importante papel que as mídias, especialmente as digitais vêm tendo nos estudos dessa área. Não podemos esquecer, como lembra a autora, de que os primeiros estudos da comunicação preocupavam-secom"a caracterização eanálise das novas práticas comunicativas que despontavam no final do século XIX e marcam o século XX: o surgimento da imprensa de massa, do rádio, da televisão (e do cinema, em menor grau)" (França, 2001, p.4).

Os estudos pioneiros dacomunicação-denominadosmasscommunication research - voltaram-se em grande medida para os efeitos e as funções dos meios de comunicação de massa, nos Estados Unidos, nos anos 1940. Também data desta época os estudos realizados sob a égide da Teoria Crítica ou Escola de Frankfurt, que ao contrário da visão positiva dos estudiosos pragmáticos, promovia uma crítica contundente à sociedade de consumo americana, com a promoção da mercantilização da cultura e a alienação dos meios de comunicação de massa, que traziam para a dimensão simbólica a mesma racionalidade do imperativo capitalista, baseado na indústria. Estas visões acerca da comunicação influenciaram um cabedal de pensadores brasileiros e escolas posteriores, que apesar de desenvolverem pesquisas próprias, ainda assim acabaram partindo da mesma premissa; qual seja, de pensar a comunicação como um discurso linear, transmissional, no qual um emissor passaria a mensagem a um receptor ou a vários receptores. Segundo Wolf (1995), o modelo informacional constituiuse como paradigma dominante nos estudos de comunicação, sendo utilizado tanto pela tradição empírica quanto pela teoria crítica.

Albuquerque (2002), ao trabalhar com a hipótese de que o campo da comunicação foi criado como uma resposta aos desafios apresentados pela comunicação tecnologicamente mediada, aponta para a importância que o sistema de broadcasting teve em sua constituição. Pare ele, circunstanciado pelo rádio e pela tevê, "o sistema de broadcasting não apenas permitiu a superação das contingências da geografia na transmissão de mensagens, como propiciou aos emissores algo muito próximo do dom da ubiquidade" (Idem, 2002 , p.2). Estas características colocaram questões que iam desde o receio de 
que essas mídias fossem usadas como instrumentos de alienação das massas ao entusiasmo daqueles que defendiam o uso democrático a serviço de todos; afinal, a possibilidade de poucos emissores atingirem um imenso público de receptores por meio do rádio e/ou da televisão criou uma nova ambiência. Com ela, o modelo E-M-R, da teoria da informação, e o conceito de sociedade de massa serviram como referenciais teóricos que durante muito tempo foram utilizados por diversos autores. Ainda segundo Albuquerque, mesmo com o advento na década de 1980 de uma mídia segmentada, este modelo continuou sendo o referencial teórico fundamental dos estudos de comunicação, em contraposição ao da sociedade de massa, que perdeu força heurística.

Cabe então discutirmos se esse modelo tripartite ainda é viável, especialmente em face das mídias digitais. O que dizem os pesquisadores brasileiros sobre a comunicação diante deste cenário? Ainda é Albuquerque que vem em nosso encalço quando aponta à insuficiência do modelo transmissional diante das novas mídias. A comunicação mediada pelo computador e um cenário no qual o excesso de informação parece senão apagar, ao menos confundir os nossos toques como o real, apontam para a impossibilidade de pensar o emissor, a mensagem e o receptor como momentos estanques, coerentes com uma lógica linear da qual a comunicação seria tributária. Nesta era de confusão, na qual, de acordo com a visão crítica de Sfez, o "tautismo " dá as cartas, "constata-se uma frenética e irrefreável multiplicação das fontes e canais e uma excessiva produção de signos-mensagem e produtos em circulação na inforrede" (Trivinho, 2001, p.123).

Diante da comunicação mediada pelos computadores, tablets e celulares, o emissor e o receptor cedem espaço, segundo Trivinho (2001), ao "indivíduo teleinteragente ciberespacial", que não espera as imagens chegarem, posto que imerso em uma atmosfera na qual a busca compulsória em pontos da rede dita a regra. O ciberespaço pressupõe uma mistura entre sujeito e objeto, impensável no processo de comunicação interpessoal e de massa. Com a implosão dessas categorias, Felinto (2011) questiona se o papel dos meios de comunicação seria mesmo o de comunicar. O protagonismo das máquinas e a importância da manutenção de seu funcionamento "na determinação das realidades humanas e dos processos de cognição" (Felinto, 2011, p.9) coloca em xeque a visão de

1 Cai por terra o esquema linear da comunicação, no qual a lógica linear baseada na mensagem do emissor para o receptor predominava. Sfez (1994, p.77) adverte que diante do excesso de informações, comunicação e imagens, as pessoas tomam o exprimir pelo representar. A esta confusão o autor dá o nome de tautismo, neologismo que mistura autismo e tautologia. 
que a comunicação seria a transmissão humana de sentidos pela mediação dos meios tecnológicos.

Em linhas gerais, perguntamos quais as características presentes nas mídias digitais que tornam visíveis novas questões e debilitam pressupostos e problemas que se constituíram como preocupações relevantes para aqueles que se debruçam sobre os estudos da comunicação? Que tipos de desafios elas colocam para o pesquisador?

Na medida em que começamos a ter contato com o material de pesquisa sobre este tema, nos deparamos com uma diversidade de termos, como, ciberespaço, cibercultura, web, internet, redes sociais, mídias sociais, ambientes virtuais, entre outros. Luís Mauro Martino (2013) alerta para as dificuldades encontradas entre os pesquisadores da área. Segundo ele, ao iniciar a pesquisa, o estudioso tem logo de início a perplexidade "diante do número de palavras usadas para definir a realidade desse campo" (2013, p.94).

Para a nossa discussão, chamamos atenção aos termos ciberespaço e cibercultura inexistentes antes do advento da internet, mas que se constituíram como categorias-chaves para a compreensão das novas tecnologias de comunicação e informação. A popularização da internet e dos computadores pessoais, além de outros equipamentos ligados às redes informáticas e comunicacionais, em meados dos anos 1990, disseminaram o uso da expressão cibercultura entre diversos pesquisadores, como uma forma de dar conta das transformações pelas quais passavam essas novas mídias. Existia a preocupação de se evitar uma perspectiva funcional ou puramente mecânica desse processo. Pesquisadores como Santaella (2003, p.25) advertiam que as mídias são antecedidas por signos, linguagens e pensamentos, e como tal, "são conformadores de novos ambientes culturais", que trazem consigo contradições que vão desde o modo econômico de produção às questões de cunho político. Daí, o termo cibercultura e sua relação direta com as tecnologias contemporâneas, representando o imaginário cultural desta época.

Se ciberespaço, espaço de fluxos, passa a ser considerado o "novo campo de comunicação na sociedade" (Lemos, 2003, p.14); cibercultura, por sua vez, aparece como um termo "guarda-chuva", que concentra inúmeros sentidos e que indica, segundo Lemos (2003, p.13):

Uma forma sociocultural que emerge da relação simbiótica entre a sociedade, a cultura e as novas tecnologias de base microeletrônicas que surgiram com a convergência das telecomunicações com a informática na década de 70 . 
Dito de outro modo, cibercultura aponta para uma nova relação entre tecnologia e sociabilidade, trazendo uma configuração cultural que combina a mixagem e a colagem de diferentes tipos de comunicação e práticas sociais, cuja origem encontra-se nas tecnologias digitais. Por isso, segundo Lemos, "cibercultura-remix" é a configuração que rege a cibercultura e se caracteriza "por três 'leis' fundadoras: a liberação do pólo da emissão, o princípio de conexão em rede e a reconfiguração de formatos midiáticos e práticas sociais" (Lemos, 2005, p.1).

Outro importante autor brasileiro, que nos ajuda a pensar a cibercultura é Francisco Rüdiger. Em sua perspectiva, a mídia digital interativa proporciona o aparecimento de fenômenos que podem ser analisados por um "cultivo de mundo" denominado cibercultura. Inserida no contexto do capitalismo e amparada pela indústria cultural, tal como as mídias tradicionais, a cibercultura, ao se popularizar como um bem de consumo de massa, junta o pensamento cibernético com a informática da comunicação. Nas palavras do autor:

Quando o progresso tecnológico e a expansão do capital confluem no sentido da exploração do campo da informática de comunicações, e, por essa via, os aparatos digitais interativos se convertem em bens de consumo de massas, estão configuradas as bases para a expansão de uma cibercultura, da colonização do ciberespaço pelos esquemas e práticas de uma indústria cultural que, desde quase um século, vinha se convertendo em princípio sistêmico de formação do nosso mundo social e histórico (2013, p.11).

Por conseguinte, mesmo havendo divergências sobre os sentidos da cibercultura, assim como de suas bases conceituais e teóricas, autores como Lemos e Rüdiger apontam para a importância deste conceito no que diz respeito às pesquisas da área de comunicação brasileiras.

Na contramão da relevância do uso do termo cibercultura, Eric Felinto desponta como uma voz no Brasil que anuncia a diminuição da popularidade deste termo na literatura especializada. Para tanto, ele cita estudiosos como Lev Manovich e Siegfried Zielinski, que renegam o termo por considera-lo antiquado e incapaz de dar conta do atual momento histórico. Felinto não para por aqui. Como indicador da perda de prestígio da cibercultura, este autor aponta para o declínio do seu uso a partir do site da Amazon, que "apresenta 34 obras com títulos que contêm a palavra 'cibercultura' publicados entre os anos 2000 e 2004, mas apenas 21 entre 2005 e 2009. Em 2010, contam-se apenas 4" (Felinto, 2011, p.2). 
Ao invés de cibercultura, Felinto defende expressões como media studies ou internet studies, pois, em sua perspectiva, elas seriam mais eficazes na definição de um domínio epistemológico do que o termo cibercultura. Diante da complexificação da comunicação no cenário das tecnologias digitais, este autor aponta para o aumento bibliográfico de um termo e o espaçamento do outro. Parafraseando Felinto, "na produção de língua inglesa, o número de títulos e obras contendo a palavra ciberculture parece cair progressivamente, ou pelo menos manter-se estável, ao passo que o uso do termo 'new media' cresce a cada ano. De 96 títulos em 2006, passamos a 142 em 2008 e a 157 em 2010" (Felinto, 2011, p.7).

A questão que o autor coloca é o motivo pelo qual, na língua inglesa, a expressão cibercultura se enfraquece. Cibercultura, segundo Felinto, retrata um imaginário dominado pelo princípio da automação, controle e conflito, no qual "a questão central é a transferência do labor humano para as máquinas" (idem, p.3). Media studies ou internet studies, por sua vez, pressupõe outra visão da tecnologia. Nela predomina atenção à expansão da criatividade humana por meio da técnica, buscando-se nas dimensões da temporalidade, corporalidade e medialidade caminhos de investigações, segundo ele, profícuos. Enquanto no ciberespaço, a hermenêutica e seu foco na interpretação de sentidos é o eixo discursivo no qual a utopia celestial da imaterialidade é apregoada; nos medias studies ou internet studies, a questão torna-se outra. A citação abaixo exemplifica bem as diferenças de perspectivas entre esses dois tipos de análise. Nas palavras de Felinto:

Se a retórica da early cyberculture foi caracterizada pelos sonhos de desmaterialização e virtualização, muitas leituras mais recentes preferem destacar a importância do corpo, do toque e das sensações em nossa interação com as novas mídias (Felinto, 2011, p.6).

E como vem ocorrendo a discussão sobre a comunicação diante das mídias digitais no contexto comunicacional estadunidense? Em um artigo que defende a importância de estudar a internet como uma mídia de massa, especialmente devido ao número cada vez maior de usuários que a acessam em todo o mundo, Merril Morris e Christine Ogan (2006) criticam o descaso de muitos pesquisadores da área de comunicação sobre esta "rede das redes". Estes autores veem a internet como uma nova comunicação tecnológica, que possibilita aos pesquisadores da área repensarem pressupostos, categorias e até mesmo terem novos insights, diante das tecnologias tradicionais da comunicação. 
Segundo estes autores, não apenas a internet, mas todo o campo da comunicação mediada pelo computador tem sido negligenciados pelos pesquisadores dos efeitos das mídias de massa, que ainda fixam suas análises em sistemas tradicionais de broadcasting e de mídias impressas. Estas, por sua vez, encaixam-se em modelos mais apropriados a tópicos de pesquisa e teorias da comunicação de massa, cujos pressupostos impedem os pesquisadores de ver a internet como uma nova mídia de massa, ainda que com outra roupagem. A tradicional visão de mídia de massa chegou ao seu limite e, segundo estes autores, caso não se questione categorias e definições arraigadas, o campo da comunicação se tornará ossificado. Parafraseando Morris e Ogan (2006, p.2; tradução nossa):

Se os pesquisadores da comunicação de massa continuarem negligenciand o o potencial de pesquisa na internet, suas teorias sobre comunicação serão menos profícuas. Não apenas porque a disciplina será deixada para trás, como também se perderá uma oportunidade de explorar e repensar respostas para algumas questões centrais da pesquisa da comunicação de massa, que estão no coração do modelo fonte-mensagem-recepção com a qual o campo tem se debatido.

Mais do que estudar a internet como uma comunicação mediada pelo computador, os autores buscam pensa-la como uma mídia de massa (mass media), não a partir de enfoques tradicionais, mas baseados em pressupostos revisados sobre o que é uma audiência de massa e uma tecnologia mediada. Para eles, na medida em que a tecnologia se transforma e as mídias convergem, os conceitos devem se tornar flexíveis e, até mesmo revisados. Diante da internet, de acordo com esses autores, os pesquisadores da comunicação devem abandonar os pressupostos teóricos tradicionais sobre as mídias de massa, ou mass media ancorados em modelos de mídia empresarial, do sistema de broadcasting e de sociedade de massa, por não serem mais adequados para se pensar o contexto atual. Desta forma, se o termo sociedade de massa não reflete a fragmentação da audiência e a convergência midiática, reduzindo a complexidade do real a um esquema prefixado; o termo mass media, por sua vez, além de muito difícil de ser definido tem suas raízes na velha expressão sociedade de massa, oriunda do século XIX. Por isso, os autores são enfáticos no que diz respeito à revitalização dos estudos tradicionais dos efeitos midiáticos no campo da comunicação norte-americano em face ao aparecimento e disseminação da internet: 
Ao criar novas configurações de emissores, mensagens e receptores, as novas tecnologias de comunicação forçam os pesquisadores a examinarem as velhas definições. O que é uma audiência de massa? $O$ que é um meio de comunicação? Como as mensagens são mediadas? (Morris e Ogan, 2006, p.4; tradução nossa).

Como os seguidores da tradicional perspectiva dos mass communications research têm apenas como objeto de estudo jornais, rádios e televisão, eles veem na comunicação mediada pelo computador uma comunicação interpessoal, deixando-a para outros campos estuda-la, como por exemplo, o da educação. A comunicação apenas considerada pelo viés tradicional minimizou, segundo Merril Morris e Christine Ogan, o papel das mídias digitais para o entendimento do processo comunicativo. Segundo os autores, diante deste outro cenário deve-se considerar o poder de penetração da mídia e não a tradicional divisão do estudo de comunicação em interpessoal, massiva ou pública, pois a internet é uma mídia de massa multifacetada, que apresenta diferentes formas de comunicação. A internet tanto tem características do tradicional modelo de comunicação de massa - emissor, mensagem, receptor, quanto o coloca em xeque ao gestar novas configurações. Por isso, "quando a internet é conceitualizada, como uma mídia de massa, torna-se claro que nem a massa, nem a mídia podem ser definidas com precisão em todas as situações, mas podem ser continuamente rearticuladas dependendo da situação" (Morris e Ogan, 2006, p.4; tradução nossa).

Jonh December (2006) é outro pesquisador norte-americano que aponta para a importância da internet, não apenas como um conjunto de ferramentas que as pessoas usam para obter informações, mais, sobretudo como uma mídia que possibilita a comunicação individual, em grupo e em massa. Para ele, a internet não pode ser considerada como uma simples mídia, mas como um conjunto de sistemas midiáticos, o que acaba dificultando definições terminológicas e unidades coerentes de análises. Em sua perspectiva, há uma miríade de pontos de vista e dificuldades quando os pesquisadores perguntam como podem falar da nova mídia, que envolve a comunicação na rede de computadores.

Este autor também questiona se as noções correntes de mídia podem ser usadas para definir a comunicação na internet, na medida em que esta se apresenta como um espaço multifacetado, diferente de mídias tradicionais como, o jornal e a televisão, por exemplo. Outro problema apontado diz respeito à falta de uma unidade de análise na imensa variedade de pesquisas sobre a internet e que se relaciona com a própria estrutura da rede. Segundo o autor, 
as pesquisas sobre a internet podem ser prejudicadas pela imensa diversidade de perspectivas, inclusive de terminologias, tornando difíceis as comparações entre os estudos, posto que impossibilita uma base comum de unidade de análise.

Nesse sentido, December (2006) argumenta que os pesquisadores têm estudado a comunicação humana através do computador e dos sistemas de redes de comunicação. Ao usarem uma variedade de modelos para definir suas análises, estes pesquisadores têm explorado um conjunto de cenários comunicacionais, cada um de um jeito. Há aqueles, por exemplo, que têm pesquisado as relações entre as características do sistema midiático e dos indivíduos que os usam. Outros têm pesquisado o componente humano da comunicação mediada pelo computador, examinando os fatores sociais e psicológicos. Há também pesquisas sobre a comunicação mediada pelo computador que exploram uma miríade de experiências on-line, que focam nas características sociais, midiáticas e de linguagem. Exemplos de uma diversidade de pesquisas afloram e são discutidas no artigo de December, que propõe em face deste caos definir unidades de análises em pesquisas sobre a comunicação na internet a fim de que haja algum consenso neste campo. Para tanto, ele identifica termos como "media space, media class, media object, and media instance as unit of analysis for Internet communication studies" (2006, p.320).

Por conseguinte, seguindo a trilha de investigadores norte-americanos, Newhagen e Rafaeli (2006) apontam para a importância da pesquisa sobre internet na área de comunicação. Ao buscarem conceitos mais robustos, eles se centram em cinco características que definem a comunicação na Net: "multimedia, hypertextuality, packet switching, synchronicity, and interactivity" (2006, p.4). Na perspectiva destes autores, a internet é um calidoscópio que ultrapassa de longe outras mídias, pois nela são veiculados textos, vozes, imagens, animação, vídeos e até mesmo cheiro. Sua hipertextualidade implode os grilhões da linearidade, tão presente nas pesquisas tradicionais da comunicação. Na internet o foco é outro: em vez da transmissão, impera o principio da anarquia e da sincronicidade atravessada por uma velocidade sem precedentes, cujo consumo pode ser feito em qualquer momento.

Livingstone (2007), por sua vez, afirma que os estudos sobre a internet são recentes, datando dos anos 1960. Muito embora a rapidez, complexidade e conteúdo da internet tenham aumentado bastante, sua infraestrutura tecnológica quase não se modificou. A transformação se deu do ponto de vista social, na medida em que a internet se tornou uma tecnologia cotidiana, difundindo-se nas casas, escolas e no trabalho a partir dos anos 1990. Ao levar 
em conta o vertiginoso aumento e difusão desta rede, Livingstone discute os debates sobre os significados e consequências da internet para a sociedade, sob o ponto de vista social, político, econômico e cultural. Segundo esta autora, para se compreender um fenômeno tão complexo, deve-se perguntar o que há de novo na internet, quais são suas características, oportunidade e perigos, porque é usada desta forma. A dificuldade de se entender a internet e suas consequências se relacionam com a constante mudança pela qual essa rede passa e seu poder de penetração cada vez maior em todo o mundo.

Assim como os demais pesquisadores, Livingstone também chama atenção para o caráter multifacetado dos estudos sobre a internet, que vão desde o campo das artes, política, antropologia, a novos e interdisciplinares campos de estudos, como estudos midiáticos, estudos de ciência e tecnologia, assim como estudos culturais. Essa amplidão de enfoques leva a teorias interdisciplinares, que ultrapassam a questão tecnológica recaindo sobre conceitos como sociedade da informação, do conhecimento e de rede. Desta forma, os estudos sobre a internet aparecem como sendo um campo menos institucionalizado, sem fronteiras muito nítidas, com raízes disciplinares diversas e metodologias ainda por serem criadas e políticas contestadas. Diante disso, Livingstone pergunta: "Podemos questionar se a institucionalização dos estudos da internet significa que uma disciplina autônoma está nascendo? Ou ainda, que progresso está sendo feito?" (2007, p.4; tradução nossa). Nas palavras da autora: "A afirmação da existência e importância dos estudos de internet encontram-se menos no carácter distinto de sua teoria ou métodos do que no carácter distinto de seu objeto" (2007, p.5).

A autora debate se há avanços sendo feitos em torno de análises críticas e explanações teóricas nas pesquisas sobre a internet. Ela aponta para o esforço que os estudiosos têm feito em identificar diferentes estágios de desenvolvimento na pesquisa acadêmica. No primeiro momento, houve uma celebração otimista do potencial transformativo da internet na década de 1990, temperada com a visão pessimista. O segundo momento veio na passagem para o século $\mathrm{XXI}$, com a descrição de usuários e usos da internet. $\mathrm{O}$ terceiro momento ainda está sendo construído e ambiciona que a descrição seja substituída pela análise. Livingstone não acredita no nascimento de uma nova disciplina acadêmica, mas em um novo e provisório campo ligado a constantes e ininterruptas mudanças tecnológicas cujas bases teóricas e metodológicas relacionem-se com disciplinas das ciências sociais e humanas. Se a internet está mudando a sociedade, então devemos nos voltar para as teorias da sociedade que analisam essas mudanças. Assim, mais do que focar na tecnologia em si, as 
pesquisas podem desenvolver um campo rico em argumentos teóricos se se voltarem a uma perspectiva interdisciplinar ou multidisciplinar.

Tal como os outros autores norte-americanos, Livingstone chama atenção para a necessidade de os pesquisadores da internet ter um foco em comum de análise. Para tanto, ela aponta para características principais desta mídia, como o fato da internet ser um sistema midiático híbrido, estruturado como uma rede, interativa e ubíqua, afetando todos aqueles que estão conectados. Parafraseando a autora:

Isto significa que as afirmações sobre o carácter distinto da internet são mais produtivas quando focadas sobre processos de informação, comunicação e poder mediados pela internet - facilitada pela extensão tecnologicamente mediada das capacidades humanas para se comunicar através do tempo e do espaço, permitindo assim um maior grau de conexão entre os atores sociais em todo o mundo - do que sobre a tecnologia em si. As tendências sociais também contribuem para moldar as mudanças da comunicação - tendências na natureza e na produção de bens e serviços econômicos, na comercialização de trabalho, sistemas de transporte, linguagem etc [...] $(2007$, p.6).

Livingstone também chama atenção ao exagero de autores que anunciam o caráter irremediável de mudanças ocasionadas pela internet. Segunda ela, há o perigo de cair em um determinismo tecnológico, na medida em que a internet é vista como um divisor de águas. O exagero sobre o poder da internet tanto sob uma perspectiva negativa quanto positiva negligencia a percepção de que a tecnologia é constitutiva da sociedade e não independente dela. Outro problema apontado pela autora é também esbarrar em um determinismo social, pois as mudanças sociais introduzidas pela internet são difíceis de serem mensuradas e algumas análises não fazem referência às especificidades da tecnologia. Uma possível saída para este impasse é tratar a tecnologia como um texto, sendo interpretada a partir de contexto social particular. Neste caso, a tendência é a atenuação de visões dicotômicas, que ora tratam a técnica como algo positivo, ora sob uma visão negativista, como se apenas duas possibilidades fossem as únicas possíveis.

\section{Considerações}

Este texto, derivado de uma pesquisa cujo resultado ainda é parcial, objetivou investigar como a comunicaçãoéabordada e de que formaé trabalhada conceitualmente pelos pesquisadores brasileiros e norte-americanos das mídias digitais. Dito com outras palavras, a nossa pergunta diz respeito ao modo como 
vem ocorrendo a discussão sobre a comunicação diante das mídias digitais no contexto comunicacional estadunidense e brasileiro. Vimos que na pesquisa brasileira a comunicação tradicionalmente tem sido pensada como algo linear, uma entidade que permite a passagem de um estado anterior a outro, como se fosse uma coisa. Esta visão ontológica perde força com o advento da internet e a implosão entre as clássicas entidades - emissor, mensagem e receptor, assim como a lógica sobre a qual se apoia. Com as mídias digitais, o ciberespaço e a cibercultura tornam-se categorias-chave, servindo de fios condutores para as análises dos pesquisadores brasileiros até o momento é que são postos em questão por alguns teóricos que defendem expressões como media studies ou internet studies. Diante da complexificação da comunicação no cenário das tecnologias digitais, Felinto (2011), por exemplo, aponta para o aumento bibliográfico do primeiro e o espaçamento do segundo.

Sob a perspectiva americana, os pesquisadores que se debruçam sobre as mídias digitais advertem para o descaso da internet pelos pesquisadores da área. Tal como os pesquisadores brasileiros, os americanos advogam que os estudos sobre a internet lançam nova luz à comunicação, que não pode mais ser pensada a partir dos pressupostos tradicionais, característicos dos estudos dos efeitos norte-americanos. Desta forma, diante da internet, os pesquisadores da comunicação devem abandonar os pressupostos teóricos sobre as mídias de massa, ou mass media ancorados em modelos de mídia empresarial, do sistema de broadcasting e de sociedade de massa, por não ser mais adequados para se pensar o contexto atual. Ainda conforme os pesquisadores, o fato de a internet se constituir como um conjunto de sistemas midiáticos acaba dificultando estudos que tenham unidades de análise e definições terminológicas comuns. Diante de tantas perspectivas, fica difícil a comparação das pesquisas, como é comum no conhecimento científico.

\section{Referências}

ALBUQUERQUE, Afonso. Os desafios epistemológicos da comunicação mediada pelo computador. In: GT Epistemologia da Comunicação da Compós, 2002, Rio de Janeiro. Anais... Rio de Janeiro: UFRJ, 2002.

DECEMBER, J. Units of analysis for internet communication. Journal of ComputerMediated Communication. 23 jun. 2006. Disponível em: <http://onlinelibrary. wiley.com/doi/10.1111/j.1083-6101.1996.tb00173.x/full>. Acesso em: 26 abr. 2014.

FELINTO, E. "Cibercultura: ascensão e declínio de uma palavra quase mágica”. 
Revista da Associação Nacional dos Programas de Pós-Graduação em Comunicação. E-Compós. Brasília, v.14, n.1, jan./abr., 2001. Disponível em: $\quad<$ http://www.compos.org.br/seer/index.php/e-compos/article/ viewFile/548/511>. Acesso em: 20 jan. 2014.

Da teoria da comunicação às teorias da mídia ou, temperando a epistemologia com uma dose de cibercultura. In: GT Comunicação e Cibercultura da Compós, Porto Alegre, RS. Anais... Porto Alegre: UFRGS, 2011. Acesso em: 26 abr. 2014.

FRANÇA, Vera. Paradigmas da comunicação: conhecer o que? Ciberlegenda. Revista do Programa de Pós-Graduação em Comunicação da Universidade Federal Fluminense. Rio de Janeiro, n. 5, 2001. Disponível em: < http://www.uff.br/ ciberlegenda/ojs/index.php/revista/article/view/314/195>. Acesso em: 20 jul. 2014.

LEMOS. André. Cibercultura: alguns pontos para compreender a nossa época. CUNHA, Paulo (orgs). Olhares sobre a cibercultura. Porto Alegre: Sulina, p. 1123, 2003.

Cibercultura remix. Artigo escrito para apresentação no seminário "Sentidos e Processos" dentro da mostra "Cinético Digital"'. Centro Itaú Cultural. A mesa tinha como tema:"Redes: criação e reconfiguração", São Paulo, Itaú Cultural, agosto de 2005. Disponível em: < http://www.facom.ufba.br/ ciberpesquisa/andrelemos/remix.pdf >. Acesso em: 23 jun. 2014.

LIVINGSTONE, Sonia. Critical debates in internet studies: reflections on an emerging field [online]. London: LSE Research Online, July 2007. Disponível em: < http:// eprints.Ise.ac.uk/1011 >. Acesso em: 24 jun. 2014.

MARTINO, Luís Mauro Sá. Repensando a(s) Teoria (s) da Cibercultura: articulações e tensões com as teorias da comunicação. Questões Transversais - Revista de Epistemologias da Comunicação. Vol. 1, n. 2, jul.-dez. 2013. Disponível em: $<$ http://revistas.unisinos.br/index.php/questoes/article/view/7661>. Acesso em: 28 jan. 2014.

MORRIS, M. \& OGAN, C. The internet as mass medium. Journal of Computer-Mediated Communication. 23 jun. 2006. Disponível em: <http://onlinelibrary.wiley.com/ doi/10.1111/j.1083-6101.1996.tb00174.x/full>. Acesso em: 5 jul. 2014.

NEWHAGEN, J. \& RAFAELI, S. Why communication researchers should study the internet: a dialogue. Journal of Computer-Mediated Communication. 23 Jun. 2006. Disponível em: <http://onlinelibrary.wiley.com/doi/10.1111/j.1083-6101.1996. tb00172.x/full>. Acesso em: 10 set. 2014. 
RUDIGER, F. Teorias da Cibercultura: perspectivas, questões e autores. Porto Alegre: Sulina, 2013.

SANTAELLA, Lúcia. Da cultura das Mídias à Cibercultura: o advento do póshumano. Revista FAMECOS, Porto Alegre, no 22, dez. 2003. Disponível em: $<$ http://revistaseletronicas.pucrs.br/ojs/index.php/revistafamecos/article/ view/3229/2493>. Acesso em: 25 jun. 2014.

SFEZ, Lucien. Crítica da comunicação. São Paulo: Loyola, 1994.

SODRÉ, Muniz. Um Novo Sistema de Integibilidade. Questões Transversais - Revista de Epistemologias da Comunicação. Vol. 1, n. 1, jan.-jul./2013. Disponível em:< http://revistas.unisinos.br/index.php/questoes/article/view/5709>. Acesso em: 20 ago. 2013.

TRIVINHO, E. O mal estar da teoria: a condição da crítica na sociedade tecnológica atual. Rio de Janeiro: Quartec, 2001.

WOLF, Mauro. Teorias da comunicação. Lisboa, Presença, 1995.

Recebido em: 05/08/2015

Aceito em: 18/09/2015

Endereço do Autor:

Tarcyanie Cajueiro Santos <tarcyanie@terra.com.br>

Universidade de Sorocaba

Rod. Raposo Tavares, km, 92.5

CEP 18023-000

Sorocaba/SP - Brasil 